\title{
The procession of constructed wetland removal mechanism of pollutants
}

\author{
Ruqiong Qin, Hong Chen \\ Guangxi Polytechnic of Construction, Nanning 530003, China
}

ABSTRACT: Constructed wetland ecosystem is a complex project, and the removal mechanism is complicated. This article is mainly summary the degradation mechanism of pollutants from the main processing and removal method of wetland functions. Constructed wetland treatment effects on plant species, substrate, microorganisms, climate and other factors.

KEYWORD: Constructed wetlands; removal mechanism; influencing factors

\section{INTRODUCTION}

If sewage collection and treatment improperly, the rural ecological environment and living environment will be damaged, then resulting in the pollution of surface water and shallow groundwater. China is vigorously promoting the construction of new rural, however, the rural economic is under development for a long-term, and the cultural quality of the residents is not high, moreover, capital, technology and talents are inadequate, sewage treatment technology becomes more passive. For the sewage treatment characteristics of the rural point of view, it should be fully taken into account in financial, personnel, maintenance and other factors of rural, as far as possible to meet the sewage treatment function. Therefore, wetland sewage treatment technology becomes more suitable, it can effectively reduce the pollution which caused by sewage in rural areas, and improve the living environment.

Dr. Seidel Germany (Wilson, B) was the wetland earliest discoverer, he found that the reed can removal inorganic and organic in 1953. And the laboratory began to conduct experiment that studied the reed features in large-scale later, the study of constructed wetlands also entered the climax at the same time. Dr. Seidel and Dr. Kickuth co-sponsored the root zone theory in 1972, and the constructed wetlands have begun to enter the application stage in 1980s, some countries began to establish reed bed system to treatment sewage. Nowadays, The United States has more than 600 constructed wetlands to treatment the industrial, agricultural and municipal wastewater.

Constructed wetland is similar to the marshes, it is builted and controlled by artificial operation in the ground, and the sewage and sludge dosing to the constructed wetlands with controlled, sewage and sludge flow in a certain direction, the constructed wetland is primarily use of soil, the artificial medium, plants, and physics, chemistry, biology of microorganisms triple synergy to treatment sewage, sludge. The mechanism of constructed wetland is adsorption, retention, filtration, oxidation-reduction, precipitation, microbial decomposition, transformation, plant shelter, residue accumulation, water and nutrient uptake and transpiration the effect of various types of animals. How about the removal of wetland? We will explanted the constructed wetland removal of organic matter, nitrogen, phosphorus, heavy metals, microorganisms and other substances in detailed.

\section{REMOVAL MECHANISMS}

\subsection{Removal of organics}

Constructed wetland have a strong ability to purify the organic matter(Yu shuili, 2011), the soil have a huge surface area, the surface of the soil particles can form a layer of biofilm, when sewage flows through the surface of the particles, a large amount of SS is blocking interception by the filler and plant roots, the insoluble organic matter also to be retained soon through wetland matrix sedimentation, filtration, adsorption, then the tiny creatures will use the organic matter, the dissolved organic matter was removed by adsorption of plant roots biofilm, absorption and metabolism of microorganisms. In the aerobic zone, the organic matter is decomposed into carbon dioxide and water by aerobic bacteria; in the anaerobic zone, organic matter is decomposed into carbon dioxide and methane by anaerobic bacteria with fermentation. Most organic matter in sewage is eventually converted to microorganisms, carbon dioxide, methane 
and water, and inorganic nitrogen, inorganic phosphorus by the heterotrophic microorganisms.

Constructed wetlands have a higher rate of removal to COD, BOD, the removal rate of most of the processing system can achieve $90 \%$. Domestic (WEN yue, 2007) research on constructed wetlands to purify municipal sewage showed that at low water concentration, the constructed wetlands to removal BOD5 are up to $95 \%$, and to removal COD are up to $80 \%$,the concentration of BOD5 in the effluent is about 10mg $/ \mathrm{L}$, SS is less than $20 \mathrm{mg} / \mathrm{L}$. Removal of COD and BOD5 of have significant correlation with various numbers of microorganisms, and indicating that removal of organic matter is mainly the action of microorganisms.

\subsection{Removal of nitrogen}

Many studies have shown that: the nitrogen in constructed wetland was removed mainly by nitrification and denitrification of microorganisms, absorption of plants, ammonia volatilization and adsorption and filtering of matrix (LU shao yong, 2006). Nitrogen is mainly forms with organic nitrogen and inorganic nitrogen in the waste water, inorganic nitrogen can be absorbed by plants, and synthesis plant protein, finally removed through harvested the plantsin constructed wetland system, but only the total nitrogen content of about 8\% -16\%inorganic nitrogen. Organic nitrogen which in constructed wetland system is more easily converted to NO3-N under the action of microorganisms, and it will also easily lead to eutrophication of surface water, so it is an important indicator of pollution that need to removal. Lietc. found that the urease activity and the removal of $\mathrm{N}$ has a significantly positive correlation in the constructed wet land soil, he considered that the urease activity in the root zone can be an evaluation indicator that the removal of nitrogen of pollutants in constructed wetland.

The removal rate of $\mathrm{N}$ is about $50 \%$ in constructed wetlands, that is the removal rate is not very high. Some studies(ZHOU chenghua, 2008) found that the removal rate of $\mathrm{N}$ can be greatly improved from $30 \%$ to $90 \%$ by added straw and methanol to improve the BOD: NO3-N ratio, the reason is that not conducive to denitrification proceeds when BOD: NO3 $-\mathrm{N}$ ratio is too low, the denitrification rate will reached a maximum when the ratio rose to 2.3. Baker's (Baker BH, 2016) study shown that the removal rate of NO3Ncan directly used C: $\mathrm{N}$ ratio when waste water containing low carbon and helium high nitrate, the speed of denitrification is maximum when $\mathrm{C}: \mathrm{N}>5: 1$.

\subsection{Removal of phosphorus}

Numerous studies shown that the phosphorus in constructed wetlands is removed mainly by absorption of plants, accumulation of microorganisms, absorption and precipitation of matrix (LU shao yong, 2006).
Firstly, the inorganic phosphorus is synthesized ATP, DNA and RNAetc.by uptake and assimilation of plants, and removed from the system through the plants harvested. Secondly, phosphorus is necessary to microbial, phosphorus bacteriaconvertedpoorly soluble organic phosphorus and phosphorus to dissolved inorganic phosphorus which is conducive to absorption by plants. Finally, phosphorusis removed by adsorption of mediaor ion exchange, the iron, aluminum, calcium compounds will affect the adsorption capacity of the media, and PAOs excess polyphosphate phosphorus also has a certain roleto removal phosphorus. Since the constructed wetland have a special aerobic and anaerobic conditions, PAOs can be adsorbed an excess of phosphorus in the aerobic state, and released excess phosphorus in anaerobic conditions, some of phosphorus will spread with the water transport, other will adsorption by the medium, because of the release of phosphorus, adsorption by media in favor of phosphorus in the local where concentration of phosphorus is higher.

The most important wayto remove phosphorus is adsorption and precipitation of matrix in constructed wetland system, there is less effect for plant adsorption of organic phosphorus, but the absorption of plant is given priority to remove inorganic phosphorus, which maybe related to the large plants, like reed plants, need for inorganic phosphorus with a longterm growth. Li ect.( LI jianbo, 2008) considered that: the adsorption by plants is a major way when at a low concentration of phosphorus, and the absorption by plants appear to be negligible when at a higher concentrations, however, the adsorption of medium is limited, that is the absorption effect will be reduced after reaching saturation.

\subsection{Removal of heavy metal}

In the constructed wetland system, heavy metal is mainly removal by chemical precipitation, ion exchange and absorption by plants etc.. Some researchers believed that the removal rateof zinc can reach $96 \%$ and the removal of iron, chromium and magnesium is also high when the residence time is 22-34h in the surface flow wetland. A study which treatmentedmining waste with planting cattails in constructed wetlands show that cattail purify the industrial wastewater contain lead, zinc is very good, the removal rate of COD, SS, $\mathrm{Pb}, \mathrm{Zn}, \mathrm{Cu}$ and $\mathrm{Cd}$ is $92.19 \%$, 99.62\%, 93.98\%, 97.02\%, 96.87\% and 96.39\%, respectively, and water quality significantly improved, the main pollutant, like TSS, $\mathrm{Pb}, \mathrm{Zn}, \mathrm{Cu}$ and $\mathrm{Cd}$ all reached the industry standard. By studying the cattail wetland system, it shown that the heavy metalis mainly accumulation and enrichment in the underground part, hence, through harvesting to remove the heavy metal. 
Some researchers believed that the removal of heavy metals is adsorption by plants in the constructed wetland. There is only $1 \%-2 \%$ heavy metals which plants absorption take up the system into contents of heavy metals. Plants removed the heavy metal also appear in aerobic action, if the oxygen content increases in the root zone, the oxidation and sedimentation of heavy metal will increase.

\section{CONCLUSION}

Constructed wetland system is a unique ecosystem which composite soil, aquatic plant, microorganisms and matrix. Due to its high efficiency, low investment, low operation costs, maintain low technology, the amount of processing flexibility and low power consumption, etc. Constructed wetland system becoming a research, application and development of sewage treatment new technology in our country, and it is very suitable for China's national conditions, especially in rural areas, small sewage treatment in urban areas.

\section{ACKNOWLEDGEMENTS}

Project source: This paper is one of the results of Guangxi scientific research projects in 2014. Project name: The pollution situation and countermeasure research in rural of guangxi. Project number: YB2014520. The approval number: GUI teach [2014] 8, scientific research.

\section{REFERENCES}

Baker BH, Kroger R, Prevost JD. A field-scale investigation of nutrient and sediment reduction efficiencies of a low-technology best management practice: Low-grade weirs. Eclolgical engineering. (2016) no.91,240-248.

DOU lei, ZHOU yongzhang, CAI limei. Removal of Heavy Metals from AMD by Constructed Wetlands. Environmental Science and Technology. (2006)no.11, 109-111.

LU shao yong, JIN xiangshan, YU gang. Nitrogen removal mechanism of constructed wetland. Acta ecologica sinica. (2006) no.8, 2670-2677.

LU shao yong, JIN xiangshan, YU gang. Phosphorus removal mechanism of constructed wetland.Ecology and Environment. (2006) no.2, 391-396.

LI jianbo, WEN yue, ZHAO xingjie. Effect of Organic Matter on Phosphorus Removal for Substrate in Constructed Wetland. Environmental science (2008) no.7, 1880-1883.

LU shoubo. Under different conditions of artificial wetlands to remove heavy metals Effect. Science and Technology Information. (2010) no.26, 431-433.

Wilson, B. H. and T. Dincer. An introduction to the hydrology and hydrography of the Okavango Delta. In: Symposium on the Okavango Delta, Botswana Soc., Gaborone, Botswana, pp. 33-48.
WEN yue, ZHOU qi, JIANG lingyan. P Degradation characteristics of organic substances in polluted surface waters treatment with horizontal subsurface flow constructed wetlands. Chian Environmental Science. (2007) no.4, 508-512.

Yu shuili, XIU chunhai, Yang yuejie. Study on removal effect of organic matters in micropolluted raw water by substrate in constructed wetland. Chian water \& wastewater. (2011) no.3, 56-58.

YANG chengsheng, LAN chongyu, SHU wensheng. Accumulation and distribution of heavy metals in artificial wetland with typhaltifolia. Technology of watertreatment (2002) no.2, 101-104.

ZHOU chenghua, LI jie, DENG chunguang. Advances in the study of Nitrogen and Phosohorus removal mechanisms in constructed wetlands. Journal of Chongqing jiangzhu university. (2008) no.4, 141-146. 